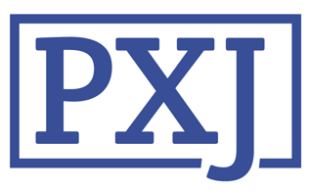

Patient Experience Journal

Volume 3 | Issue 2

Article 10

2016

\title{
The evaluation of an information booklet in the use of effective patient communication in the setting of thoracic anesthesia
}

\author{
Camille Guillot Miss \\ University of Edinburgh, UK \\ Gerry Keenan Dr \\ Department of Anaesthesia, Critical Care and Pain Medicine, School of Clinical Science \& The University \\ of Edinburgh
}

Follow this and additional works at: https://pxjournal.org/journal

Part of the Anesthesiology Commons, and the Health Communication Commons

\section{Recommended Citation}

Guillot C, Keenan $\mathrm{G}$. The evaluation of an information booklet in the use of effective patient communication in the setting of thoracic anesthesia. Patient Experience Journal. 2016; 3(2):57-66. doi: 10.35680/2372-0247.1153.

This Article is brought to you for free and open access by Patient Experience Journal. It has been accepted for inclusion in Patient Experience Journal by an authorized editor of Patient Experience Journal. 


\section{The evaluation of an information booklet in the use of effective patient communication in the setting of thoracic anesthesia}

\section{Cover Page Footnote}

Acknowledgements Many thanks to Gerry Keenan, who supervised this project and made its realisation possible. I gratefully acknowledge Gillian Nelson, medical photographer, for obtaining pictures for the production of the booklet, Keith Wylde for help towards printing, and Simon Riley for advice about both these tasks. Many thanks to the University of Edinburgh for covering the financial cost of printing the booklets. Much gratitude to all the staff in the thoracic ward, for filling out questionnaires and helping me integrate into the ward, especially Ailsa Oswald, Catherine Smart, and Athina Pandelis. Thanks to Margaret McDouguall, medical statistician, for help and advice and the staff at Printing.com for producing a good quality product. 


\title{
The evaluation of an information booklet in the use of effective patient communication in the setting of thoracic anesthesia \\ Camille Guillot, University of Edinburgh, c.guillot@sms.ed.ac.uk \\ Gerry Keenan, Department of Anaesthesia, Critical Care and Pain Medicine, School of Clinical Science \& The University of Edinburgh,gerry.keenan@nbslotbian.scot.nbs.uk.
}

\begin{abstract}
Effective communication is crucial in assuring a good patient experience during an in-hospital stay. In some settings, such as thoracic anaesthesia, patients are given a heavy load of new complex information, in a very limited space of time. Written information, such as patient information booklets, could help as an aid memoir and improve patient's subjective understanding and preparedness for procedures. This study aims to produce a booklet, specifically targeted at thoracic anaesthesia, and to evaluate it using a linguistics framework in relation to the patient experience and clinical communication. For the study, a booklet was produced in the context of thoracic anaesthesia - a setting where the doctor-patient interaction is limited by time factors. The booklet was produced with reference to the BALD criteria. A questionnaire was given to patients with the booklet, focussing on patient's subjective reflections on the effects of the booklet. The patient questionnaires showed that readability and comprehensibility of the booklet were high $(96 \%$ and 93\%, respectively). After having read the booklet, there was a statistically significant increase in patients feeling well informed, knowing about side-effects, what would happen in the anaesthetic room, and who to contact regarding any questions, compared to before. According to patients, giving information booklets at the time of admission could benefit patients. They are seen as an effective way of enhancing doctor-patient communication, in a setting where time could limit this interaction. They can be used effectively as a means of increasing patient's perceived knowledge and thus improving the patient experience.
\end{abstract}

\section{Keywords}

Clinical communication, thoracic anesthesia, patient-centered approach, information booklet, patient experience

\section{Introduction}

Preoperatively, anesthesiologists deliver large quantities of verbal information to their patients ${ }^{1}$. During these consults, the anesthesiologist must be informative, sometimes giving information which may be both anxietyprovoking yet important, whilst building a rapport with their patient ${ }^{1}$. This highlights the importance of effective communication.

During consults, patients receive information solely in the spoken form - it is usually delivered spontaneously and quickly ${ }^{2,3}$. This may result in patients not fully understanding the facts going to them, or an inability to recall them after the consultation ${ }^{2,3}$.

Important aims of the consultation are to educate the patient about the anesthesiologist's role, pre-operative preparation and the content and risks of the anesthetic plan ${ }^{1}$. A study has shown that to meet these aims, 50 to 100 pieces of information are routinely given verbally to patients during pre-operative consultations ${ }^{4}$. Therefore, unsurprisingly, the goals of the anesthetic consult have been found to be limited by human memory ${ }^{1}$. In fact, a study by Sandberg et al. showed that subjects spontaneously recalled less than $25 \%$ of verbal information given during an anesthetic consult video ${ }^{1}$. Furthermore, this study demonstrated the phenomenon known as "the primary effect", whereby the majority of points recalled were given towards the beginning of the consultation video ${ }^{1}$.

Furthermore, a study found that from doctors' perspectives, giving too much information during a single consult is disadvantageous to communication ${ }^{5}$. Large quantities of information may have a psychological cost to patients, increasing anxiety, symptoms or side effects and causing confusion which could in turn lead to nonadherence $^{5}$.

Firstly, comprehension is a vital precursor step to memory ${ }^{1}$. However, it is not sufficient, as the information must be transferred from working memory to long term memory to be spontaneously recalled ${ }^{1}$. This leads to the use of cognitive psychological theory: providing written 
information for further reference can increase recall by minimizing task demands, in this case, from free recall ${ }^{1}$.

When patients make decisions regarding management plans, especially whilst balancing the risks and benefits of an intervention, written information can prove invaluable ${ }^{2}$. Written information ensures consistency, whilst stimulating questions and helping recall ${ }^{6}$. There has been a growing interest towards the type of design used for delivery of health information ${ }^{2}$. With this growth, we recognize that the written information supplied should be effective, communicable and appealing, as poorly design or unclear information is of no benefit, or worse, could mislead patients ${ }^{2}$.

Written information, such as information booklets, have been shown successful in the context of preoperative anesthesia $^{7}$. A Canadian study enrolled 322 surgical patients during preadmission clinics ${ }^{7}$. The test group received an information booklet after clinic, whilst the control group did not ${ }^{7}$. The two groups were then asked to fill-out a questionnaire regarding anesthesia. The test group scored significantly better than the control group, with median scores of 9 and 5 , respectively $(p<0.0001)^{7}$. The study concluded that illustrated patient information booklets, when written at an appropriate level, is an effective means of communication in the context of anesthesia 7 .

Health Care Improvement Scotland guidelines for preoperative anesthesia state patients should have access to relevant information, with availability of leaflets customized for local use ${ }^{8}$. In this study, we will produce an information booklet tailored specifically for undergoing thoracic surgery at the Royal Infirmary of Edinburgh, with facts specific to this setting. By using a questionnairebased evaluation, we can appraise whether patients will feel more informed having read the booklet, and whether this strategy of customizing booklets to a pre-determined patient groups could be employed by others in order to improve the patient experience.

Patients' experience is enhanced by using a patientcentered approach of care and feeling part of the decisionmaking process. Recent research looked at patient satisfaction in 297 individuals who were put in an active, collaborative role in the decision-making for the anesthetic method used for their surgery 9 . The majority of patients for satisfied (93.4\%) and felt respected $(97.7 \%)^{9}$. Written information can help patients during the decision-making process, thus helping to improve satisfaction.

Therefore the aims of this study will include:

1. Evaluating the benefits of a patient information booklet on patient experience, using questionnaires to assess patient response. The booklet will be given at the time of admission, a practical setting for intervention.

2. Determine whether a written aide memoir can make patients feel subjectively better informed.

\section{Methods}

\section{Development of the booklet}

The booklet was developed by the authors of this paper, with consultant anesthesiologist input. Medical photography was used for all pictures, after written was consent gained from patients. At this stage in the production, patient input was not used. Due to the complexity and technicalities of thoracic anesthesia, specialist input was solely used in the productive of the booklet, with the aim to adapt to patient response following patient evaluation.

To ensure successful communication, several aspects of written information were important to consider when producing the booklet. These considerations include design, readability and content ${ }^{10}$.

\section{Design}

Booklets which are visually appealing are more likely to be noticed by patients ${ }^{11}$. Hence, an appealing design is vital to get patient interested in reading the contents. Design includes aspects such as:

- Pictures: Patients find medical information more approachable if pictures are involved ${ }^{11}$. Medical photography was recruited to get high-quality images, and written consent from patients gained prior to being photographed.

- Font size: This should be 12 point or greater, for ease of reading ${ }^{11}$.

- Structure: Patients find text easier to read when broken into "moves"12. Moves refer to a series of sections in the text, which follow logically from one to another ${ }^{12}$. It is helpful if the moves are separated by headings, and long paragraphs are avoided ${ }^{11,12}$.

- Headings: Studies have found patients prefer when headings are structured like questions e.g. "What are the side effects of anaesthesia?"12. These types of headings are particularly helpful when patients are looking for specific information within the booklet ${ }^{12}$.

The Baker Able leaflet design (BALD) criterion (table 1) is internationally renowned for good design characteristics for information booklets ${ }^{10}$. This criteria was used as a guideline during the booklet's development.

\section{Readability}

To maximize the effectiveness of information taken in, the level of written language should be appropriate for the patient group 7 . This allows for easy comprehension and understanding of the written information, resulting in improved knowledge and adherence to disease 
Table 1. BALD criteria, adapted from (13), B\&W black and white

\begin{tabular}{|c|c|c|c|c|}
\hline \multirow[b]{2}{*}{ Design Characteristics } & \multicolumn{4}{|c|}{ Points } \\
\hline & 3 & 2 & 1 & $\mathbf{0}$ \\
\hline Line $50-89 \mathrm{~mm}$ long & & & Yes & No \\
\hline Separation between lines & $>2.8 \mathrm{~mm}$ & $2.2-2.8 \mathrm{~mm}$ & & $<2.2 \mathrm{~mm}$ \\
\hline Lines unjustified & & & Yes & No \\
\hline Serif typeface & & Yes & & No \\
\hline Type size & 12 point & 10-11 point & 9 point & $<9$ point \\
\hline First line indented & & & Yes & No \\
\hline Italics & & 0 words & 1-3 words & $\geq 4$ words \\
\hline Headings lower case & & & Yes & No \\
\hline Headings standout & & Yes & & No \\
\hline Positive advice & & Positive & & Negative \\
\hline Boxed text & & & $0-1$ Box & $>1 \mathrm{Box}$ \\
\hline Numbers all Arabic & & & Yes & No \\
\hline Pictures & $\begin{array}{l}\text { Word count not } \\
\text { replaced }\end{array}$ & In between & In between & None/B\&W \\
\hline Number of colours & 4 & 3 & 2 & 1 \\
\hline White space & $>40 \%$ & $30-39 \%$ & $20-29 \%$ & $<20 \%$ \\
\hline Paper quality & $>90 \mathrm{gsm}$ & 75-90gms & & $<75$ gms \\
\hline
\end{tabular}

management ${ }^{5}$. Readability formulas are a simple way of evaluating the reading level of particular texts, over 40 different formulas exist ${ }^{10}$.

Flesch-Kincaid Grade Level (FK-GL) and the Flesch Reading Easy (FRE) scores are both available on Microsoft Word and were used to assess readability of the booklet. FK-GL score is based on the average number of syllables per word, and words per sentences ${ }^{14}$. To calculate these scores, text from the booklet was transferred into Microsoft Word 2013, and the readability statistics analyzed using the Spelling \& Grammar tab.

\section{Content}

As previously mentioned, the content of the booklet included the aims of the standard anesthetic pre-op consultation: the role of anesthesiologists, pre-operative preparation and contents and risks of the anesthetic plan ${ }^{5}$. Very importantly, the content of the booklet must be accurate and obtained from an up-to-date and reliable source ${ }^{15}$.

An information booklet issued by the Royal College of Anaesthetists was used as a reference ${ }^{15}$. Next, a preliminary booklet assessment meeting was arranged with a consultant anesthesiologist at the Royal Infirmary of Edinburgh to ensure validity of the text. The booklet was handed out to surgeons, anesthesiologists, nursing and junior staff on the thoracic team at the RIE for a secondary assessment by health professionals. A total of 7 health professionals gave feedback on the booklet: 1 surgeon, 3 anesthetists, 1 senior nurse and 2 junior doctors. This analysis looked for factual error. No factual errors were found by this group of health professionals, but a few typos were found and amended before the booklet was distributed to patients.

Finally, the booklet was professionally printed by Printing.com. This ensured a consistent high-quality product.

\section{Evaluation of the booklet}

45 patients undergoing thoracic surgery were enrolled during their admission at the RIE. The booklet was given at the time of admission - there is no pre-operative anesthetic clinic at the RIE. The intervention period lasted for three weeks, as this was the time allocated to investigators for the research project. Due to low admissions rates for thoracic surgery, an average of three patients a day, patients were not randomized, and all patients listed for thoracic surgery were asked to be included in the study. During the three weeks period, only 2 patients refused to be part of the study, and were excluded.

The patients were given a booklet and a questionnaire to fill. The questionnaire was based around the linguistic framework of leaflet evaluation, designed by Gardner et $a l^{16}$. The model evaluates three components:

1) Readability This is discussed previously, in the "development of booklet" section. However, a subjective view of readability was acquired with yes/no answer to the question "did you find the text hard to understand?".

2) Comprehensibility Syntax, or sentence structure, is the major linguistic factor in a reader's ability to construct meaning ${ }^{16}$. Gardner et al. suggest evaluating this using multiple-choice questions ${ }^{16}$. This involves withdrawing 
Figure 1. Statements given to patients for evaluation of booklet's 'effect

1. I know who to contact if I have any questions regarding my anesthesia
2. I feel well informed about the anesthesia I will receive
3. I am nervous about my surgery
4. I know what to expect while getting ready for surgery
5. I am aware of the possible side effect of the anesthesia

chunks of information from the booklet, asking participants to read each chunk and selecting the most appropriate option from a list of five ${ }^{16}$. The correct answer was chosen before handing out the questionnaire. It was decided that a question was left unanswered, it would count as "wrong".

Important features of this analysis are that non-correct options were reasonable and not absurd ${ }^{16}$. Care was taken so participants could not guess the right answer on the basis of pattern recognition within the text ${ }^{16}$.

3) Effect $A$ successful booklet should elicit a predetermined response from the reader ${ }^{16}$. Responses can be cognitive (e.g. understanding, knowledge, expectations), affective (e.g. concern, relief) or behavioral (e.g. adhering to medication ${ }^{16}$. These longer-term responses are difficult to assess, and it is proposed that specific outcomes of the booklet should first be decided, and assessment based around these ${ }^{16}$.

It was decided that objectives of the booklet should be tested using a holistic approach - using subjective opinions from patients. This is a reflection of the type of patient-centered approach advocated by the General Medical Council (GMC), and would emphasize the patient's experience from their point of view. After reading the booklet, patients should feel more informed about the basics of the anesthetic consult. The effect of the booklet on levels of anxiety was also considered.

To investigate these points, patients were given a list of statements (Figure 1). Before receiving the booklet, participants were asked to rank these statements a 5-point Likert scale from "strongly disagree" to "strongly agree". Then, they were given the booklet to read. They were seen about half an hour later with the same statements and scale.

For roundedness, patients were given a set of yes/no questions regarding the design and format of the booklet.

Furthermore, a short verbal interview was conducted upon completion of the questionnaire. The interview was conducted by the same investigator to standardize results, and lasted approximately 20 mins. During the interview, open-ended questions were asked to obtain patient- specific qualitative responses to the information booklet. For instance, these questions included, "What are you overall thoughts about the booklet?" and "Could anything make the booklet better?". The interviews had the aim of defining future patient input into the booklet. To pick up the main themes of the short interviews, a grounded analysis approach was used; using key words for general themes brought up by patients. This approach was used as to avoid making hypothesis about patients' views, which might have limited the topics of the discussion. Thus, the patient rather than the interviewer was the lead of the conversation.

\section{Statistical Analysis}

Data were analysed and presented as descriptive statistics.

To evaluate the matched pairs obtained from the "effect" section of the patient questionnaire (i.e. Likert items before and after reading the booklet), the Wilcoxon signrank test was used. The data was analysed on IBM SPSS. In this study, a high level of statistical significance was pertained if $\mathrm{p}<0.01$.

\section{Results}

\section{Development of booklet}

Design

The BALD score of the booklet was 27 (Table 2).

Points were lost as line length exceeded the recommended measurement, and the font was sans-serif.

Results from the patient questionnaire showed that 100\% (45) of the participant liked the look of the booklet, and $98 \%$ (44) finished reading the whole booklet. 93\% (42) found the font size easy to read. Finally, 91\% (41) patients liked the pictures. Of those who didn't, 3 participants hadn't noticed them, and one patient hadn't liked the picture of the cannula.

\section{Readability}

The FRE score was calculated as 65.2, and the FK-GL score was 7.0. 
Table 2. BALD score of booklet by criteria point.

\begin{tabular}{lcc} 
Criteria & Booklet measurement & $\begin{array}{c}\text { Points } \\
\text { achieved }\end{array}$ \\
\hline Length of lines & $124 \mathrm{~mm}$ & $\mathbf{0}$ \\
Line separation & $4 \mathrm{~mm}$ & $\mathbf{3}$ \\
Lines unjustified & Yes & $\mathbf{1}$ \\
Serif typeface & No & $\mathbf{0}$ \\
Type size & $14 \mathrm{pt}$ & $\mathbf{3}$ \\
Paragraph indented & Yes & $\mathbf{1}$ \\
No italics & Yes & $\mathbf{2}$ \\
Lower case headings & Yes & $\mathbf{1}$ \\
Positive advice & Yes & $\mathbf{2}$ \\
Boxed text & 1 box & $\mathbf{1}$ \\
Arabic numbering & Yes (page no.) & $\mathbf{1}$ \\
Pictures & Word count not replaced & $\mathbf{3}$ \\
Number of colours & $>4$ & $\mathbf{3}$ \\
White space & $>40 \%$ & $\mathbf{3}$ \\
Paper Quality & $150 \mathrm{gsm}$ & $\mathbf{3}$
\end{tabular}

\section{Patient evaluation}

\section{Readability}

This is discussed previously, under the "development of booklet" heading. In terms of patient evaluation, $96 \%$ (43) of participants found the text easy to understand.

\section{Comprehensibility}

A total of 42 patients $(93 \%)$ completed the comprehensibility section of the form. Cumulatively, $92.9 \%(195 / 210)$ of comprehension questions were answered correctly. $81 \%(34 / 42)$ got all 5 questions right, $12 \%(5 / 42)$ got 4 out of $5,2 \%(1 / 42)$ got 3 out of 5 , and $5 \%(2 / 42)$ got 2 out of 5 .

\section{Effect}

For each of the data sets, the histogram produced using the differences between scores showed symmetry. Thus, all assumptions were met for the Wilcoxon Signed-Rank test.

After reading the booklet, patients were felt better informed about anesthesia, what to expect before surgery, the side effects of anesthesia and knowing how to contact with questions (Table 3).

The distribution of the scores for each questions before and after reading the booklet are illustrated in Figure 2.
During the short qualitative interview at the end of the questionnaire, topics most often mentioned by patients were that many believed the booklet could benefit patients (25) and that it was an effective means of communication (10). However, it was suggested the booklet should be given earlier e.g. posted with their surgical information pack (10). Some felt the booklet could be of great benefit to their families, in understanding what their loved ones would be going through (13). Patients particularly liked the simple language, and that some more complex medical terms were clearly explained (5). Findings are summarized in Figure 3.

\section{Discussion}

According to the BALD criteria, a score of 27 puts the booklet in the 'above standard' category, in terms of good layout and design ${ }^{10}$. This score was higher than the average score of 22 for leaflet evaluated in a study by Adepu \& Swamy ${ }^{10}$. This was reflected by the patient questionnaire: a high proportion of the patients liked the layout, pictures, and though the text was easy to read.

The FK-GL formula is a measure which rates text based as a US grade-school level ${ }^{14}$. For instance, a score of 6.0 means that a student in grade 6 would understand the text ${ }^{14}$. In the US population, the average reading/writing level is seventh to eight grade, therefore the booklet 
Table 3. Median scores before and after reading the booklet, and median score between the two score.

\begin{tabular}{|c|c|c|c|c|c|}
\hline Question & $\begin{array}{l}\text { Median Score before } \\
\text { reading booklet }(\mathrm{x})\end{array}$ & $\begin{array}{l}\text { Median score after } \\
\text { reading booklet }(y)\end{array}$ & $\begin{array}{l}\text { Median change } \\
\text { in scores }\end{array}$ & $Z$ value & $\mathrm{P}$ value \\
\hline $\begin{array}{l}\text { Feeling well informed about } \\
\text { anesthesia }\end{array}$ & $\begin{array}{c}4 \\
\text { Agree }\end{array}$ & $\begin{array}{c}5 \\
\text { Strongly Agree }\end{array}$ & 1 & 4.802 & $<0.001$ \\
\hline $\begin{array}{l}\text { Feeling nervous about } \\
\text { surgery }\end{array}$ & $\begin{array}{c}4 \\
\text { Agree }\end{array}$ & $\begin{array}{c}4 \\
\text { Agree } \\
\end{array}$ & 0 & 0.184 & 0.845 \\
\hline $\begin{array}{l}\text { Knowing what to expect } \\
\text { before surgery begins }\end{array}$ & $\begin{array}{c}4 \\
\text { Agree }\end{array}$ & $\begin{array}{c}5 \\
\text { Strongly Agree } \\
\end{array}$ & 1 & 4.883 & $<0.001$ \\
\hline $\begin{array}{l}\text { Knowing the side effects of } \\
\text { anesthesia }\end{array}$ & $\begin{array}{c}3 \\
\text { Neither }\end{array}$ & $\begin{array}{c}4 \\
\text { Agree } \\
\end{array}$ & 1 & 4.965 & $<0.001$ \\
\hline $\begin{array}{l}\text { Knowing who to contact with } \\
\text { questions about anesthesia }\end{array}$ & $\begin{array}{c}4 \\
\text { Agree }\end{array}$ & $\begin{array}{c}4 \\
\text { Agree }\end{array}$ & 1 & 4.807 & $<0.001$ \\
\hline
\end{tabular}

should have a FK-GL score between 7.0 and 8.0 ${ }^{14}$. The FK-GL score was 7.0.

The FRE score was 65.2. This suggests that the text is somewhat challenging to read, as a score of 70 and above is considered "easy to read" 5 . In an Indian study, the average FRE score was 80 when leaflets for five chronic illnesses e.g. hypertension were analysed. However, the demographics in this population would differ from the Western population of my study; India has a literacy rate of less than $50 \%$ compared to $99 \%$ in the $\mathrm{UK}^{10,12}$. In contrast, an Australian study reviewed 30 leaflets and found an average FRE score of $51^{10}$. The demographics of this study would arguably be more comparable. Moreover, over $95 \%$ of the participants did not subjectively find the text hard to understand. Therefore, although the FRE score could be improved, it did not seem to pose a problem for patients.

Measuring the reader's response was tricky, as there is not a systematic set of criteria developed for this purpose as of yet $^{12}$. It was decided that the assessed response should be the patient's subjective feelings e.g. whether they felt well informed about anesthesia. Although this is important from the patient's point of view, it does not necessarily reflect whether they are objectively 'well informed'. For instance, the patient might think they know how to prepare for surgery, but in fact did not understand that they had to stop some medication beforehand.

A possible development on this point would be to use a similar study design to Cheung et al . Patients were met during pre-admission clinics by anesthesiologists, and randomly allocated to a test or control group. The test group receives the information booklet, whilst the control group does not ${ }^{7}$. Both groups are given a multiple-choice test about anesthesia and the scores compared ${ }^{7}$. However, in the same way, although patients who have read an information booklet may objectively know more about a certain area in their care, they may not feel better informed and still remain confused or unsatisfied with their knowledge base.

In future patient evaluation of written information could aim to amalgamate both subjective and objective viewpoints. A comparison of objective scores, similar to the one obtained by Cheung et al., and patient's own subjective scores, could be used to appraise whether a patient's own feelings reflect their actual knowledge base.

This illustrates the need for the development of an evidence-based criteria for the evaluation of patient responses to written information. Such criteria would aid in the evaluation of effective communication and better the in-hospital patient experience.

The booklet was written and reviewed by those in the medical profession as to ensure the content of the booklet was accurate. Furthermore, due to the specific time period during which this research had to be conducted, this was also a means of same time and allowing for more time for the patient evaluation with the final completed version of the booklet.

However, it was found that experts in subject areas are not good at identifying problems that lay people may face when reading the written information ${ }^{18}$. Also, in previous research focusing on patient evaluation of information booklets, as few as 10 participants were needed to identify most flaws, which may have been acceptable for time limits ${ }^{19}$. Nonetheless, small participant numbers limit generalizability, and larger samples would have been needed for the strength of the data.

This study is subject to important limitations. Whether or not participants previously received anesthesia wasn't 
Figure 2. Bar charts to show number of patients in each Likert item before and after reading the survey for a) feeling well informed about the anesthesia they will receive, b) feeling nervous about their surgery, c) knowing what to expect in the anesthetic room, d) knowing the side effects of anesthesia and e) knowing who to contact with questions regarding anesthesia

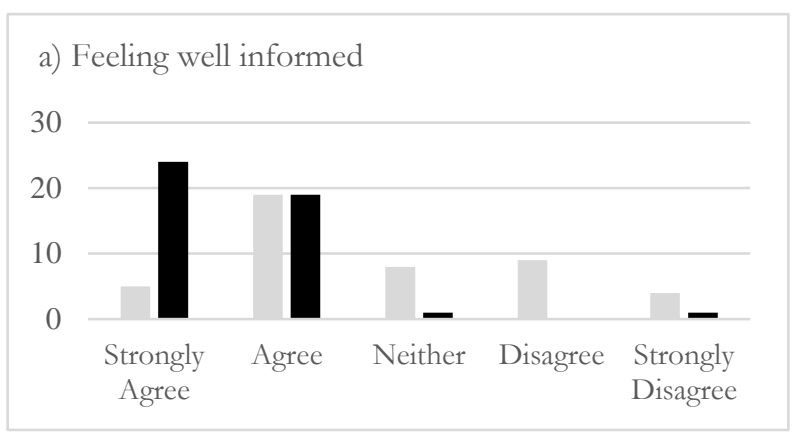

c) Knowing what happens in the anesthetic room

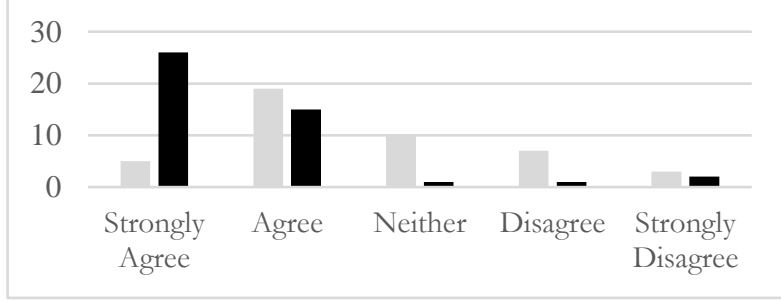

e) Knowing how to contact about questions

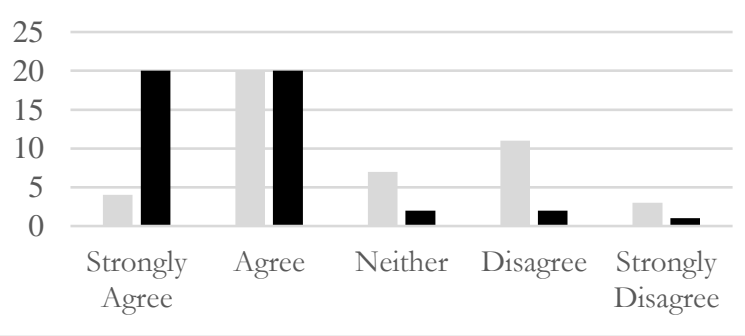

controlled for. This was excluded because it would have been a difficult variable to control - some patient had received general anesthesia a couple of weeks before the study, others over thirty years ago. The effect of the booklet may have been underestimated if some had recently had anesthesia. It would also be difficult to know whether the knowledge patients felt they had was attributable only to the booklet. This was somewhere controlled by having a score before and after reading the booklet, done within a short interval, so that any change in knowledge should be due to what was read in the booklet.

The short interviews were conducted by the same interviewer to ensure consistency of responses. However, the interviewer was also involved in the production and evaluation of the booklet which may have contributed to

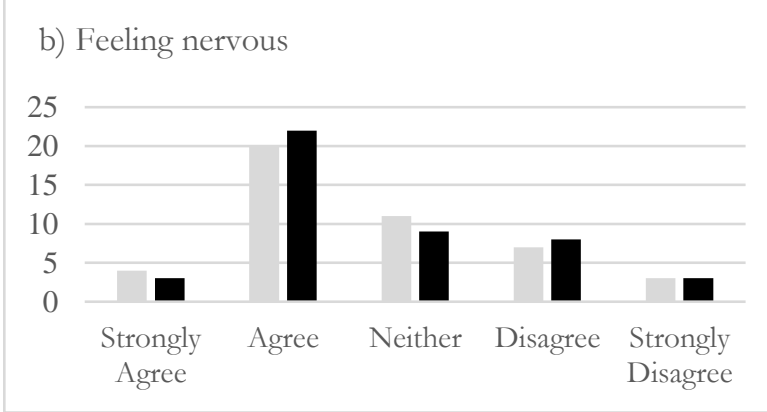

d) Knowing side effects of anesthesia

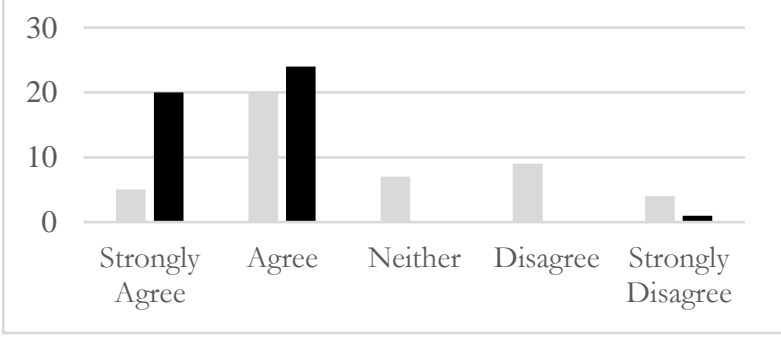

$\underline{\text { Key }}$

Before reading booklet

After reading booklet desirability bias. Patients were asked open questions such as "what are your thoughts on the booklet?" to ensure that the conversation was led by their own thoughts, and not directed by the interview. Ideally, another individual not involved in the project may have led a second interview and compared patient's opinion.

Interestingly, the 'feeling well informed' scores before reading the booklet were quite high: the median score being 4, or "agree". Future studies could compare scores obtained at admission, with scores obtained at an earlier time e.g. surgical clinics, or sent home with surgical information packs. Comparing the change in these scores would help to identify the best point of intervention for 
Figure 3. Bar charts to show patient responses from short qualitative interviewing about their thoughts on the patient information booklet. Some patients responded with more than 1 opinion. 5 patients did not offer any comments.

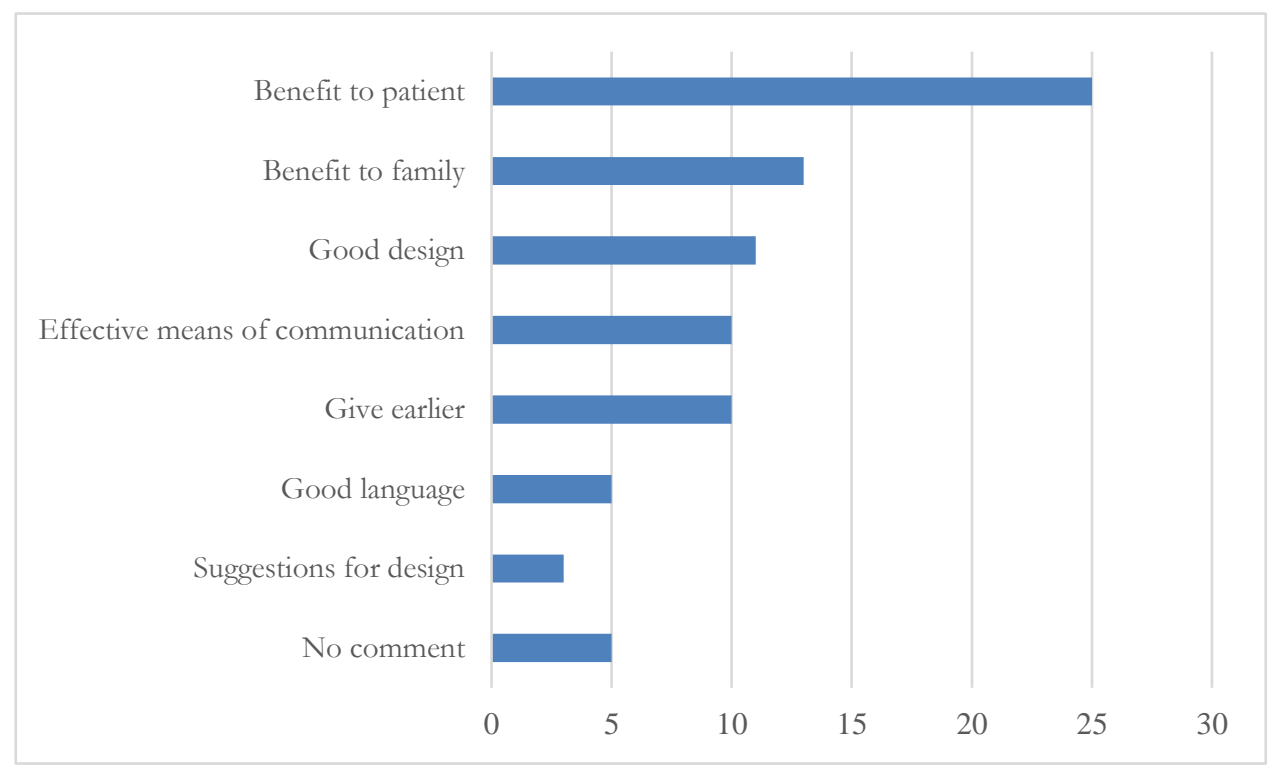

patient education. Taking into account feedback from some of the patients during the qualitative interview, it would seem beneficial to give out the booklet earlier i.e. in patients' surgical packs sent at home.

Another recurring theme in the short qualitative interviews was that a written information booklet could also benefit relatives, for instance those who may not be able to be present during the consultation. Information booklets could provide key information to relatives while patients are being assessed ${ }^{2}$. This can leave time for these advocates to think of questions, which could help in the decision making and overall patient support and satisfaction ${ }^{2}$. This could be further researched by conducting a similar study with patient's relatives.

After reading the booklet, there was not a significant change in patients' anxiety levels prior to surgery. Preoperative anxiety has been acknowledged as an important issue for patients undergoing surgery ${ }^{9}$. In elective cases, it was found that anesthesia is a bigger source of anxiety than the surgery itself ${ }^{20}$. Preoperative anxiety can be due to the lack of information, and thus giving out the booklet at an earlier time of the intervention could give patients a longer time to appraise the information and formulate questions they may have ${ }^{21}$. Another qualitative questions asking patients about their specific anxieties could help pinpoint any particular issues which could be introduced into the booklet. This technique could be applied to any evaluation of written information, warranting patient involvement in the production of information leaflets.

Furthermore, it would be worthwhile to investigate other pre-operative techniques to reduce patients' anxieties. In a recent study, a study group was visited by ICU nurses the day before their surgeries ${ }^{22}$. These nurses provided a structured counseling session and patients' anxiety levels were assessed by Zung self-rating anxiety scale (SAS) ${ }^{22}$. The intervention showed the experimental group had significantly less anxiety symptoms than the control group $(33.3 \%, 58.3 \% \text { respectively, } \mathrm{p}=0.001)^{22}$. This approach could be employed while giving out the information booklet to thoracic patient, with a designated trained member of staff going through the information with patients.

In pediatric populations, using distraction methods, such as storytelling, was shown to reduce pre-operative anxiety $^{23}$. Meanwhile, music therapy was shown to reduce anxiety levels in men undergoing transurethral resection of the prostate ${ }^{24}$. Methods such as these should be considered for reducing stress in patients pre-operatively and may be combined with more conventional approaches such as information booklets and counselling.

\section{Conclusion}

The responses from the patients' questionnaires was overwhelmingly positive, especially as seen during the short qualitative interview. Patients felt more informed 
following reading the booklet, and many thought it could be of great benefit to patients and their families.

This study considers the possibility of giving information booklets in an alternative setting e.g. at admission. Although scores for 'who to contact', 'feeling well informed', 'side effect knowledge', and 'anesthetic room preparation' improved after reading the booklet, qualitative data suggests patients prefer receiving the booklet earlier in the course of clinical care.

\section{Implications for Practice}

Information leaflets can enhance communication between healthcare professionals and patients, in a setting where doctor-patient contact is limited, as in anesthesia. They can assist patients in understanding important information, thus improving compliance. Patients put great importance on the timing for receiving written information. This could be verified through further research evaluating patient responses to written information at different time points during the surgical pathway. Furthermore, receiving situation-specific information e.g. in thoracic anesthesia can help patients to feel more informed in an area which they may lack knowledge and may not know where to find the answers to their questions, thus improving the patient experience.

\section{Disclosure}

We confirm all patient identifiers have been removed or disguised so the patients described are not identifiable and cannot be identified through the details of the story.

\section{References}

1. American Society of Anesthesiologists. Deficits in Retention for Verbally Presented Medical Information. Anesthesiology. (2012). 117: 772-9

2. Knappa P, Wanklynb P, Raynora DK, Waxman R. Developing and testing a patient information booklet for thrombolysis used in acute stroke. International Journal of Pharmacy Practice (2010). 18: 362-369

3. Wilson $\mathrm{M}$ et al. Customers' recall of information given in community pharmacies. Int $\mathrm{J}$ Pharm Pract 1992; 1: 52-59

4. Sandberg EH, Sharma R, Wiklund R, Sandberg WS: Clinicians consistently exceed a typical person's short-term memory during preoperative teaching. Anesth Analg (2008). 107: 972-8.

5. McGrath JM. Physicians' perspectives on communicating prescription drug information. Qual Health Res. (1999). 9: 731- 45

6. Cheung A, Finegan BA, Torok-Both C, DonnellyWarner N, Lujic J. A patient information booklet about anesthesiology improves preoperative patient education. Can J Anaesth. (2007). 54: 355-60

7. O'Connor AM et al. Decision aids for people facing health treatment or screening decisions. Cochrane Database Syst Rev 2009; 2: CD001431.

8. Quality Improvement Scotland. National Health Service in Scotland. Anaesthesia: care before, during and after anaesthesia: National overview. (2005). Clinical Standards Board for Scotland.

9. Hwang SM, Lee JJ, Jan JS, Gim GH, Kim MC, Lim SY. Patient Preference and Satisfaction with Their Involvement in the Selection of an Anesthetic Method for Surgery. (2014). J Korean Med Sci. 29(7):1030-1

10. Adepu R, Swamy MK. Development and Evaluation of Patient Information Leaflets (PIL) Usefulness. Indian J Pharm Sci. (2012). 4: 174-8.

11. Hirsh D, Clerehan R, Staples M, Osbrone RH, Buchbinder R. Patient assessment of medication information leaflets and validation of the Evaluative Linguistic Framework (ELF). Patient Educ. Couns. (2009). 77: 248-54.

12. Clerehan R, Buchbinder R, Moodie J. A linguistic framework for assessing the quality of written patient information: its use in assessing methotrexate information for rheumatoid arthritis. Health Educ Res. (2005). 20: 334-44.

13. Mathew EM, Rajiah K, Sharma KK. Consumer's perception on design and layout of consumer medical information leaftlets on obesity and lipid lowering drugs. J Clin Diagn Res. (2013). 12: 2800-2.

14. Kumaran A, Yohannan JK, Jijie J, Palanisamy S, Jacob S. Development and implementation of patient infomraiton leaflet on hypertension and to assess its effectiveness. Int J Phar'Tech Res. (2009). 1, 712-9.

15. The Royal College of Anaesthetists (2008). Anaesthesia explained. 3rd ed. London: The Royal College of Anaesthetists. Available online: http://www.aagbi.org/sites/default/files/Anaesthes ia $\% 20$ explained.pdf

16. Garner M, Zhenye N, Francis J. A framework for the evaluation of patient information leaflets. Health Expect. (2012). 15: 283-94.

17. National Literacy Trust. (2015). How many illiterate adults are there in England?. Available: http://www.literacytrust.org.uk/adult_literacy/illiter ate_adults_in_england. Last accessed 10th April 2015.

18. Lentz L, De Jong M. The evaluation of text quality: expertfocused and reader-focused methods compared. IEEE Trans Prof Comm 1997; 40: 224 233.

19. Knapp P et al. Performance-based readability testing of participant information for a Phase 3 IVF trial. Trials 2009; 10: 79 
20. Ramsay MA. A survey of pre-operative fear. Anaesthesia 1972; 27: 396- 402.

21. Tolksdorf W, Berlin J, Rey ER, Schmidt R, Kollmeier W, Storz W, Ridder T, Schaetzle P. Preoperative stress. Study of the mental behavior and parameters of physiological stress in nonpremedicated patients during the preoperative period. Anaesthesist 1984; 33: 212-7.

22. Yang CH, Tan YH, Jian JX, Meng XX, ,Meng FY, Wu YL, Chen QL, Ma LL, Wang LX. Pre-operative education and counselling are associated with reduced anxiety symptoms following carotid endarterectomy: a randomized and open-label study. European Journal of Cardiovascular Nursing. 2012; 11(3): 284-288

23. Tunney AM, Boore J. The effectively of a storybook in lessening anxiety in children undergoing tonsillectomy and adenoidectomy in Norhtern Ireland. Compr Pediatr Nurs. 2013; 36(4): 319-35]

24. Yung PMB, Chui-Kam S, French P, Chan TMF. A controlled trial of music and pre-operative anxiety in Chinese men undergoing transurethral resection of the prostate. Journal of Advanced Nursing. 2002; 39(4): 352-359 